\title{
Estimation of local plastic deformation in a bulk of polycrystalline materials
}

\author{
Monika Vyskocova*****, Maros Martinkovic*, Martin Necpal* and Maros Vyskoc** \\ * Slovak University of Technology in Bratislava, Faculty of Materials Science and Technology in Trnava, Institute of Production \\ Technologies, Jana Bottu Trnava, Slovak Republic \\ ** Slovak University of Technology in Bratislava, Faculty of Materials Science and Technology in Trnava, Advanced Technologies Research \\ Institute, Jana Bottu Trnava, Slovak Republic \\ ***Corresponding Author: monika.vyskocova@stuba.sk
}

Submitted : 30/07/2020

Revised : 04/08/2021

Accepted : 14/08/2021

\begin{abstract}
This article deals with the local plastic deformation analysis after cold forming. The technology of drawing seamless steel tubes was used to obtain cold-formed samples. The tubes were manufactured by a Tinius Olsen $300 \mathrm{ST}$ tensile tester with a $6^{\circ}$ and $12^{\circ}$ die drawn without and with an inner mandrel. Based on orientation size recalculated by stereology and applying Monte Carlo method, a mathematical conversion model was developed. The implemented model together with surface measurements and structure characteristics was used to get the orientation to the size of the deformation. Thus, the actual (logarithmic) deformations and local stresses were determined. The comparison of experimentally measured values of the actual local plastic deformation with the deformation calculated found on the model simulation in the Deform program defined the significance of the differences assessed by means of a statistical T-test. All differences in the values of the local plastic deformation with respect to the position were evaluated as statistically insignificant, and therefore, the difference between the experimental calculation and the simulation is random.
\end{abstract}

Keywords: Deformation; Stereology; Grain boundary; Orientation.

\section{INTRODUCTION}

The changes in structure that occur during the deformation process are related to the material's anisotropic properties. The extent to which the 3D microstructural characteristics can be obtained from cross-sectional observations remains unclear. Miyoshi, E. et al. also pay attention to this problem, claiming that there additionally exists some disagreement as to whether a cross-sectional view of 3D grain growth can be fully approximated by $2 \mathrm{D}$ growth (Miyoshi, 2018). To clarify the development of the texture, it is important to understand the deformation process, and it cannot be achieved without knowing the changes that occur throughout the volume of material. From a macroscopic point of view, the deformation determination is usually relatively simple by the change in the sample dimensions after deformation. However, the size of the deformation and the change in structure may vary microscopically in the sample volume (Matoušek, 2015). Several ingenious methods, including stereological ones, are used to create a model of the material microstructure in various simulation programs and quantitative monitoring of the microstructure or material properties. These methods can significantly help in the precise investigation of 
grained structures (Martinkovič et al., 2020). Stereology provides practical techniques for extracting quantitative information about three-dimensional material from measurements made on two-dimensional planar sections of material (Baddeley et al., 2005). It is promising, extremely simple, cheap (Martinkovič et al., 2020), and an important and effective tool in many microscopy applications. Stereology utilizes statistics and stochastic geometry (especially in the deduction of sampling) (Rønn-Nielsen et al., 2017). As Martinkovič, M. et al. presented, the most convenient way for estimation of the local plastic deformation is the measurement based on stereological principle enabling to determine the degree of grains orientation. Using stereological method an oriented test lines enables to determine the degree of grains orientation in any area of polycrystalline pieces (Martinkovič et al., 2020). Because there are several stereological techniques, according to Gokhale, it is necessary to compare the results obtained with another, independent method (Gokhale, 2019). For this study, a simulation model was developed in Deform program.

\section{EXPERIMENTAL PROCEDURE}

\section{Material Characteristics}

The drawing semifinished product is a cold drawn steel type 11353 (EN SPT360) with a diameter of $28 \mathrm{~mm}$ and a wall thickness of $4 \mathrm{~mm}$. This material is a single-purpose steel to produce seamless tubes (Table 1, Table 2) suitable for tubular structures of statically stressed components (also welded), pipelines for oil, diesel, water, steam, air, gas, pipe fittings, etc. (Steel grades, 2019).

Table 1. Chemical composition (in wt.\%) (Steel tubes, 2019).

\begin{tabular}{|c|c|c|}
\hline $\mathbf{C}[\mathbf{\%}]$ & $\mathbf{P}[\%]$ & $\mathbf{S}[\%]$ \\
\hline 0,18 & 0,05 & 0,05 \\
\hline
\end{tabular}

Table 2. Mechanical properties (Steel tubes, 2019).

\begin{tabular}{|c|c|c|}
\hline $\operatorname{Re}(\mathrm{MPa})$ & Rm (MPa) & A $(\%)$ \\
\hline 235 & 340 & 25 \\
\hline & 440 & \\
\hline
\end{tabular}

\section{Drawing Machine and Equipment}

The tubes were drawing on the Tinius Olsen 300ST tensile testing machine with maximum force of 300kN, test speed 0.001-500 $\mathrm{mm} / \mathrm{min}$, and maximum crosshead travel $1198 \mathrm{~mm}$ (Tinius Olsen, 2020). During the drawing process, dies were used with a calibrating cylinder with a diameter of $25 \mathrm{~mm}$ and drawing angles of $6^{\circ}$ and $12^{\circ}$. The process was carried out using the mandrel and without one as well. The tubes were recrystallized annealed before drawing. 


\section{Sample Preparation}

To capture the whole drawing process, the tube was cut into three sections (Figure 1). The samples were cut in orthogonal, tangential, and longitudinal planes of the deformed tube (Figure 2a), similar to Necpal et al. (2019). Metallographic cuts were chosen that on one longitudinal plane of the section there was only a linear orientation, and on the other longitudinal plane of the section, there was a superposition of linear and planar orientation. The planar orientation was captured on the cross section. Metallographic preparation of samples was performed according to the standards for macroscopic and microscopic analysis of samples STN EN ISO 17639: 2014. The pressed samples were etched in 3\% Nital, and the microstructure was analyzed using a light microscope (NEOPHOT 32).

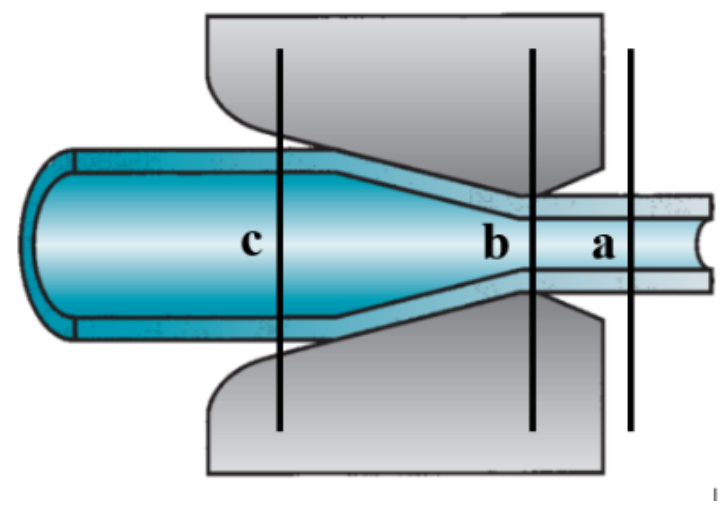

Figure 1. Crosswise sections of (a) final work size, (b) bearing surface, (c) initial state (Groover, 2011).

In each section (Figure 1), the sample was observed in three positions, that is, surface, center, and interior, as shown in Figure 2b, and the spacing between them was $1 \mathrm{~mm}$, starting $1 \mathrm{~mm}$ from the inner edge.
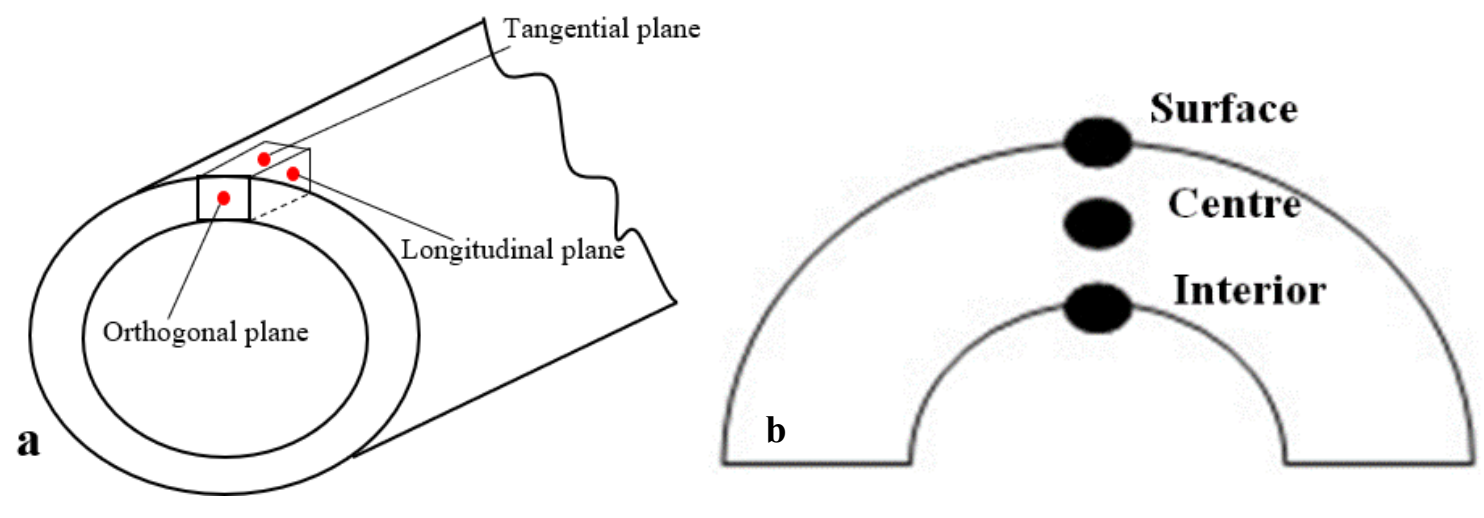

Figure 2. a) Metallographic cuts and planes (Necpal et al., 2019).

b) Example of positions observed on the sample. 


\section{Calculation}

The local strain was evaluated from the microstructure by stereological measurement of the degree of grain boundaries orientation. The anisotropic microstructure was decomposed into isotropic and planar oriented components using quantitative metallography (Saltykov stereology methods with oriented test lines) (Martinkovič et al., 2016). However, the orientation is not the same as deformation; a model of changing the orientation of grain boundaries to deformation was used (Martinkovič, 2017).

The approach is based on three basic equations:

- Definition of the deformation:

$$
\varphi=\int_{l_{0}}^{l} \frac{1}{l} d l
$$

- Definition of the degree of orientation in a given direction: $\quad O=\frac{\left(S_{V}\right)_{O R}}{\left(S_{V}\right)_{T O T}}$

$\left(\mathrm{S}_{\mathrm{V}}\right)_{\mathrm{OR}}$ specific surface of the oriented part of the grain boundary;

$\left(\mathrm{S}_{\mathrm{V}}\right)_{\text {тот }}$ the total specific surface area of the grain boundary.

- Volume conservation law: $\quad \mathrm{V}_{0}=\mathrm{V}_{\text {def }}$,

from which follows a true deformation $\varphi_{1}+\varphi_{2}+\varphi_{3}=0$ [10].

The numbers of intersections of the test lines with grain boundaries in both the orthogonal and parallel directions (Figure 3) at $90 \%$ confidence were converted to the degree of orientation using equations (1-4).

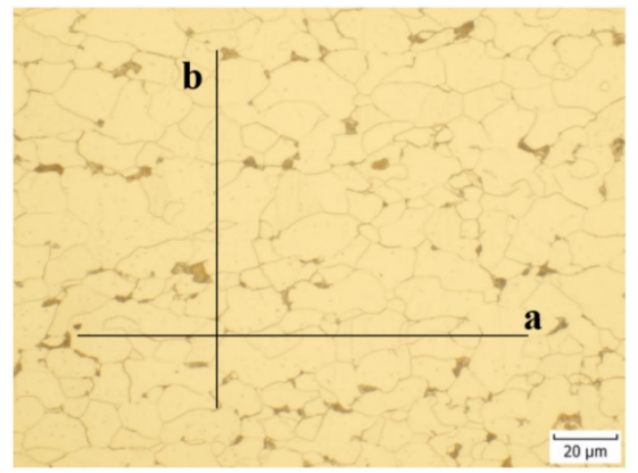

Figure 3. Test lines (a) parallel direction, (b) orthogonal direction.

The absolute measurement error was calculated based on the following equation:

$$
\varepsilon_{r}=\frac{K t}{\sqrt{p}}
$$

$\mathrm{t}=1,6449$ (table value for a probability value of $90 \%$ )

$$
\mathrm{K}=1
$$


The value of $\varepsilon_{\mathrm{r}}$ ranged between 0.03 and 0.09 . The length of test lines was $0.16 \mathrm{~mm}$ (400x magnification). The oriented test lines were placed random, and their number ranged from 20 to 30 in one direction.

The mathematical model created using the Monte Carlo method allows the estimation of local plastic deformation from the estimation of the anisotropy of the microstructure at any place of the body with any state of initial deformation (Martinkovič, 2016). Before the final calculation of the local deformation, it was necessary to know the values in each direction and section, as follows (Martinkovič et al., 2018):

- Total length of all lines:

$$
\mathbf{L}=\text { length of test line } \mathrm{x} \text { number of lines. }
$$

- Number of intersections per unit length of test line:

$$
\mathbf{P}_{\mathbf{L}}=\text { number of all intersections on the line } / \mathrm{L} \text {. }
$$

- The degree of orientation is calculated separately for the linearly oriented system $\left(\mathrm{O}_{\mathrm{L}}\right)$ and the areaoriented system $\left(\mathrm{O}_{\mathrm{P}}\right)$ of the sample:

$$
O_{L}=\frac{\frac{\pi}{2}\left[\left(P_{L O}\right)-\left(P_{L P}\right]\right.}{\frac{\pi}{2}\left(P_{L O}\right)+\left(2-\frac{\pi}{2}\right)\left(P_{L P}\right)}
$$

$O_{p}=\frac{P_{L O}-P_{L P}}{P_{L O}+P_{L P}}$

$\mathrm{P}_{\mathrm{LO}}$ - number of points per unit in linear section and orthogonal direction;

$\mathrm{P}_{\mathrm{LP}}$ - number of points per unit in linear section and parallel direction.

Based on the values of the degree of orientation (Op a $\left.\mathrm{O}_{L}\right)$ for individual systems, the quantities " $\varphi 2$ - $\varphi 3$ " and $\varphi 1$ were calculated using the Monte Carlo conversion method.

The mathematical relation $\varphi_{1}+\varphi_{2}+\varphi_{3}=0$ was used to calculate the remaining transformations. The specific values of $\varphi_{1}, \varphi_{2}, \varphi_{3}$ are presented in Figures 6a, 8a, and 10a in chapter Results.

\section{RESULTS}

For the analysis of local plastic deformation, nine samples were metallographically prepared and subsequently evaluated by the Saltykov method of oriented test lines (each one in orthogonal, tangential, and longitudinal section), representing 27 metallographic planes. Three samples were taken from a tube drawn without mandrel, three other samples from a tube drawn with mandrel through a die with a drawing angle of $6^{\circ}$, and the last three samples from a tube drawn with mandrels through a die with a drawing angle of $12^{\circ}$. Deformation of the initial state was evaluated first for each analyzed tube before the drawing process because the deformations of manufactured semifinished products were not zero value, and the calculated ones in the other sections were subtracted from the given values. To compare the calculated values for local plastic deformation after cold drawing, a simulation model was developed in Deform program. A similar method of calculation and subsequent comparison was used by Q. Zhu and his colleagues 
(Zhu, 2007). Considering the tube material as plastic and assuming isotropic hardening, yield function was set to Von Mises. As the temperature stays lower in cold drawing, the forming material properties do not vary and, therefore, can be supposed to be independent of temperature fluctuations. The forming tools (mandrel and die) were considered as rigid bodies. The boundary condition that represents the speed of drawing is set to 9 m.min- 1 . The friction coefficients between of the tube and die as well as the tube and mandrel under lubricated condition are determined using FE modelling by comparing measured and simulated plug, die, and drawing forces, and the friction shear was set to 0.05421 . The tube domain was filed by tetrahedron mesh. The tube domain was divided into subdomain for optimum meshing with the rib filling subdomain having the smallest elements. The tube section around rifling with visible mesh is illustrated in Figure 4 (Necpal et al. 2020).

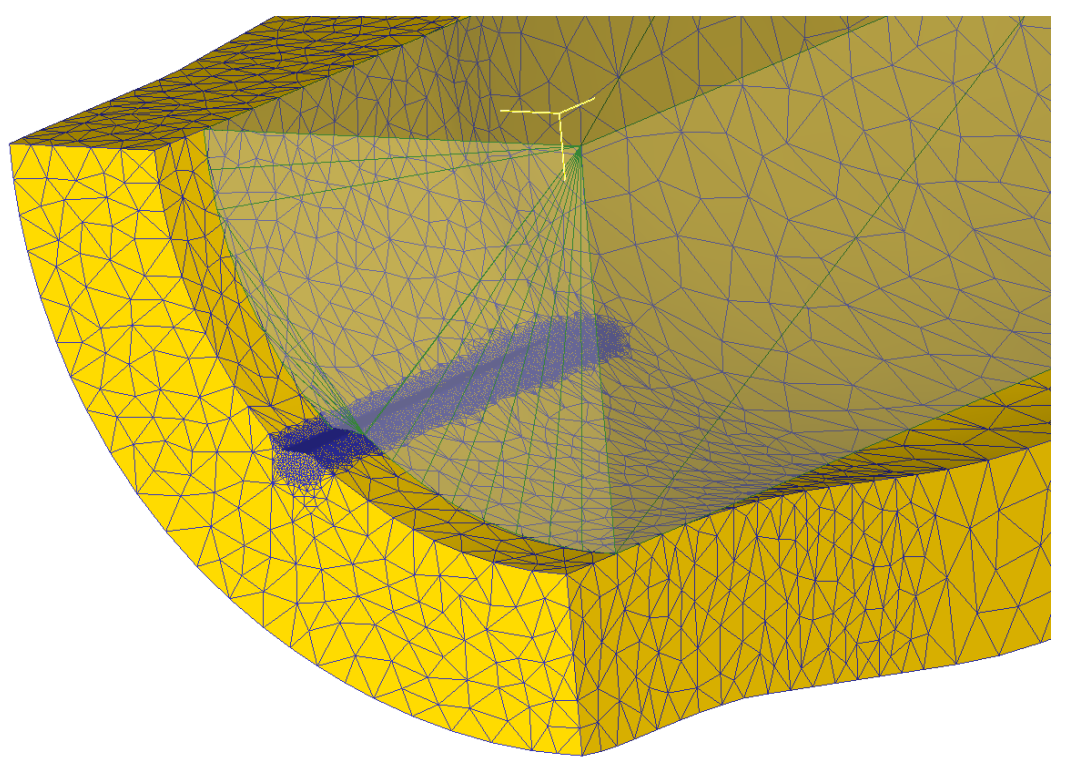

Figure 4. The section of the tube around rifling with visible mesh (Necpal et al. 2019).

Similar to Foadian et al., the simulation was interrupted during drawing in certain steps in order to monitor the development of deformation in various areas, for example, undeformed zone, partially deformed tube in the die, and finally, deformed drawn tube. In these areas, three points were selected, that is, surface, center, and inside of the material, and the amount of deformation was measured in them (Foadian et al., 2016). Based on the stereological calculations mentioned in the Calculation chapter, the values of local plastic transformations for individual sections were obtained (Figures 6 a; 8 a; 10 a) and are shown in black in the tables. The values of local plastic deformation calculated by simulation in the Deform program are displayed in red, and the absolute values of their difference are marked in blue. For each drawing method, the microstructures before and after drawing are compared (Figures 5, 7, and 9). Figures $6 \mathrm{~b}, 8 \mathrm{~b}$, and $10 \mathrm{~b}$ show the distribution of the local plastic transformations according to the simulation in the Deform program. 


\section{Tube Drawn Without Mandrel in the Inner Diameter}

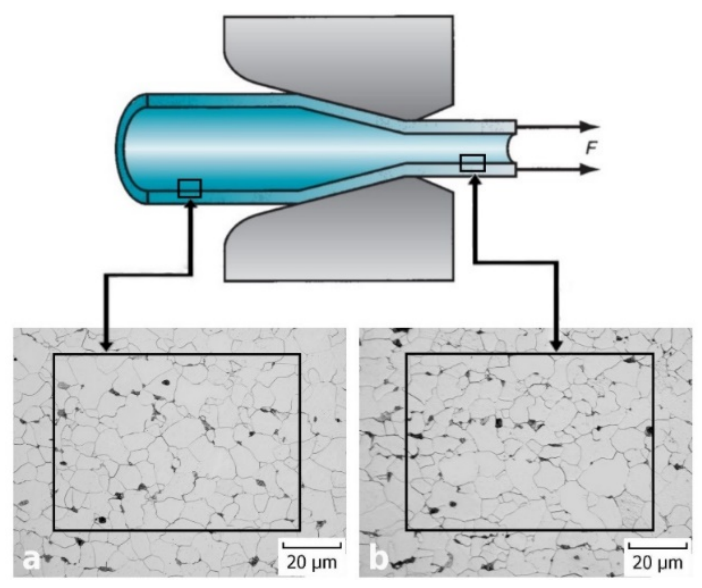

Figure 5. Microstructure of (a) material before deformation; (b) deformed material.

Microstructure before deformation (Figure 5 a) is characterized by an average grain size of $9,41 \mu \mathrm{m}$, and the microstructure of the final deformed tube (Figure $5 \mathrm{~b}$ ) has an average grain size of $6,96 \mu \mathrm{m}$.

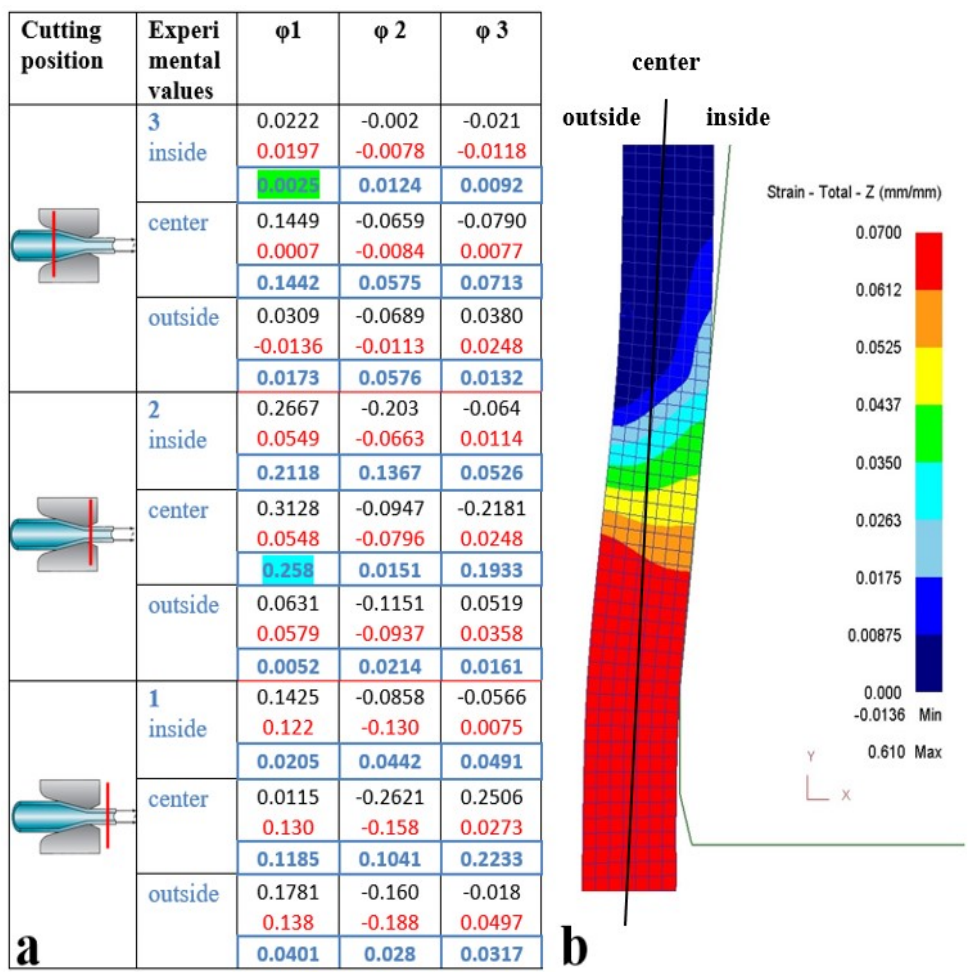

Figure 6. (a) Experimental values of local plastic deformation by stereology 1) drawn, 2) inside the die, and 3) enter to die; (b) distribution of local plastic deformations by simulation. 
The green background of the value in the tables (Figure 6 a) represents the lowest value of the difference between the calculated and simulated value (Figure $6 \mathrm{~b}$ ) of the local plastic deformation. On the other hand, the blue background displays the largest deviation. In the case of drawing, the deviation in $70 \%$ of the calculations was less than 0.1. The significance of individual differences was assessed by means of a statistical T-test. All differences in the values of local plastic deformation with respect to position were evaluated as statistically insignificant, and thus, the difference between the experimental calculation and the simulation is random $(\mathrm{P}>0.05)$.

\section{Tube Drawn with Mandrel Through a Die with a Drawing Angle of $6^{\circ}$}

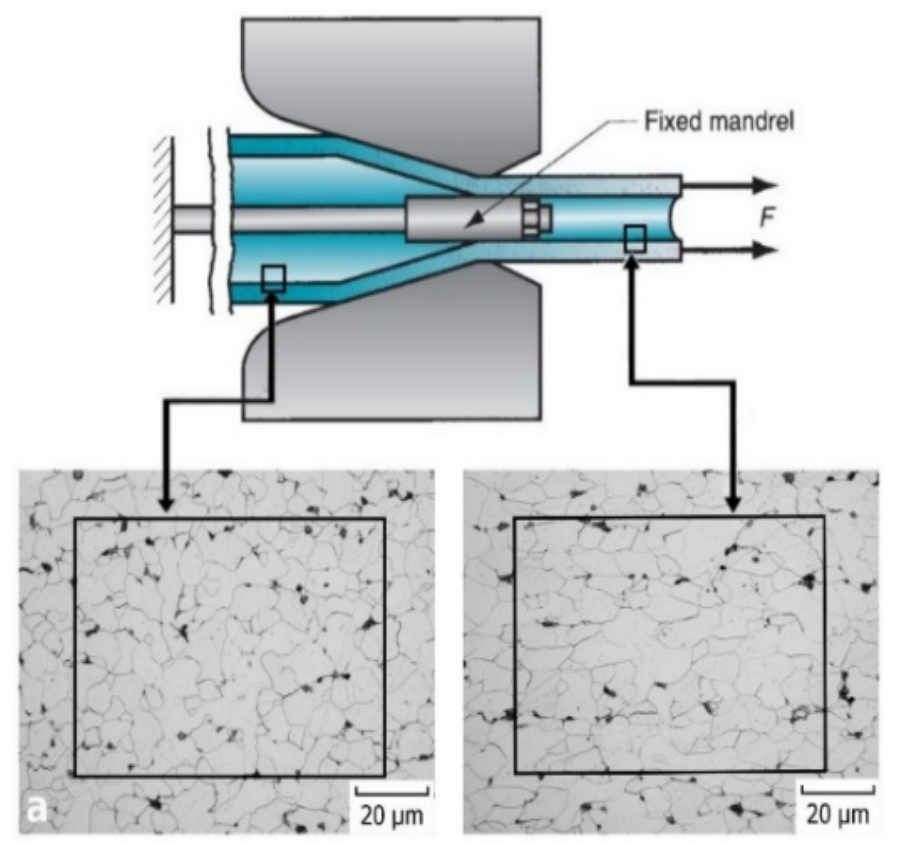

Figure 7. Microstructure of (a) material before deformation; (b) deformed material.

In case of drawing the tube with a mandrel in the inner diameter through a $6^{\circ}$ die, the difference between the initial state before deformation and the state after deformation is more visible (Figure 7). A change in the orientation of the grains in the direction of tension can be observed. It is in line with the scientific results of Karanjule et al. (2018). The grain size of undeformed material is on average (Figure 7a) 11,43 $\mu \mathrm{m}$. On the other side, the deformed material (Figure $7 \mathrm{~b}$ ) is characterized by an average grain size of 7,62 $\mu \mathrm{m}$. 


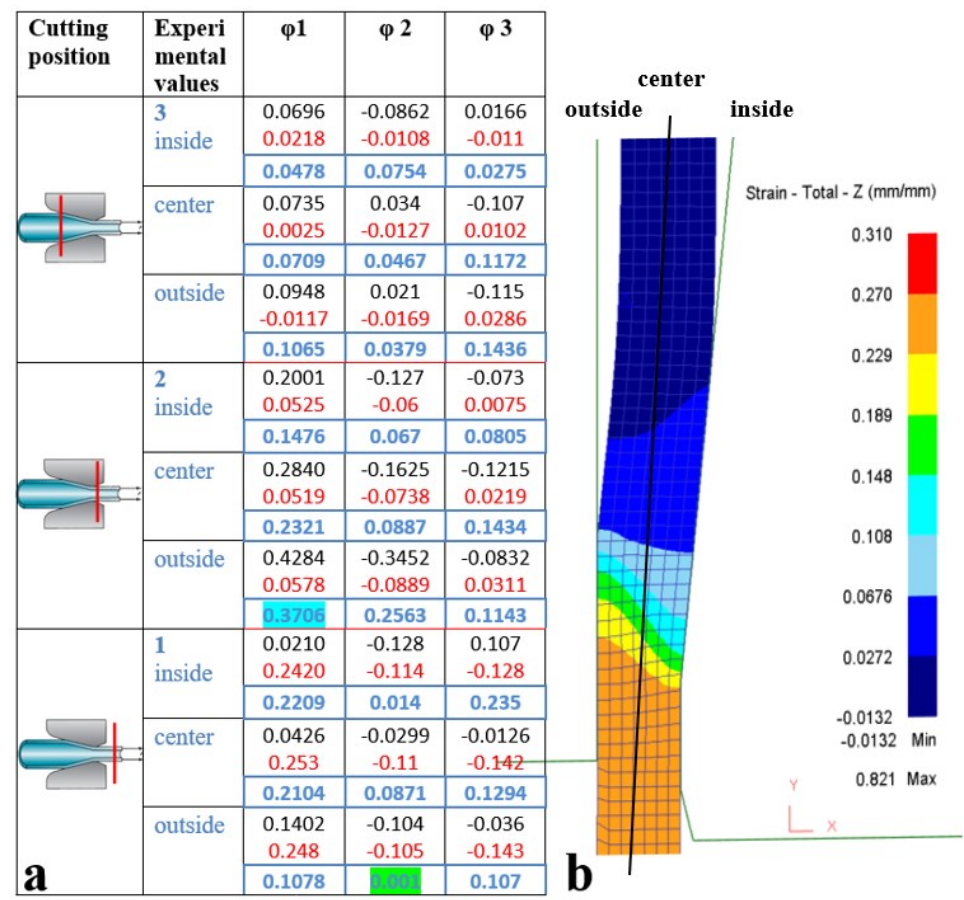

Figure 8. (a) Experimental values of local plastic deformation by stereology 1) drawn, 2) inside the die, and 3) enter to die; (b) distribution of local plastic deformations by simulation.

The maximum deviation between the experimentally calculated and simulated values

(Figure 8 a) was 0.3706. The significance of the individual differences was also assessed by statistical T-test as statistically insignificant, and therefore, the determined difference between the experimental calculation and the simulation (Figure $8 \mathrm{~b}$ ) is random $(\mathrm{P}>0.05)$.

\section{Tube Drawn with Mandrel Through a Die with a Drawing Angle of $12 \circ$}

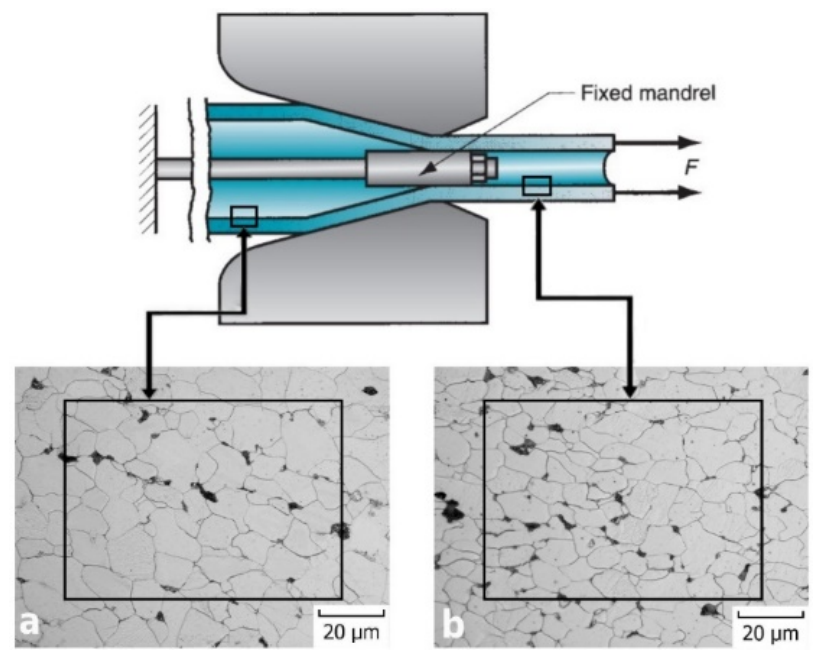

Figure 9. Microstructure of (a) material before deformation; (b) deformed material. 
In Figure 9, as in the previous case, a change in the orientation of the grains relative to the initial state can be observed. The difference between the initial average grain size (Figure 9 a) and deformed grain size (Figure 9 b) is firstly $13,3 \mu \mathrm{m}$, and in the second case, $8 \mu \mathrm{m}$.

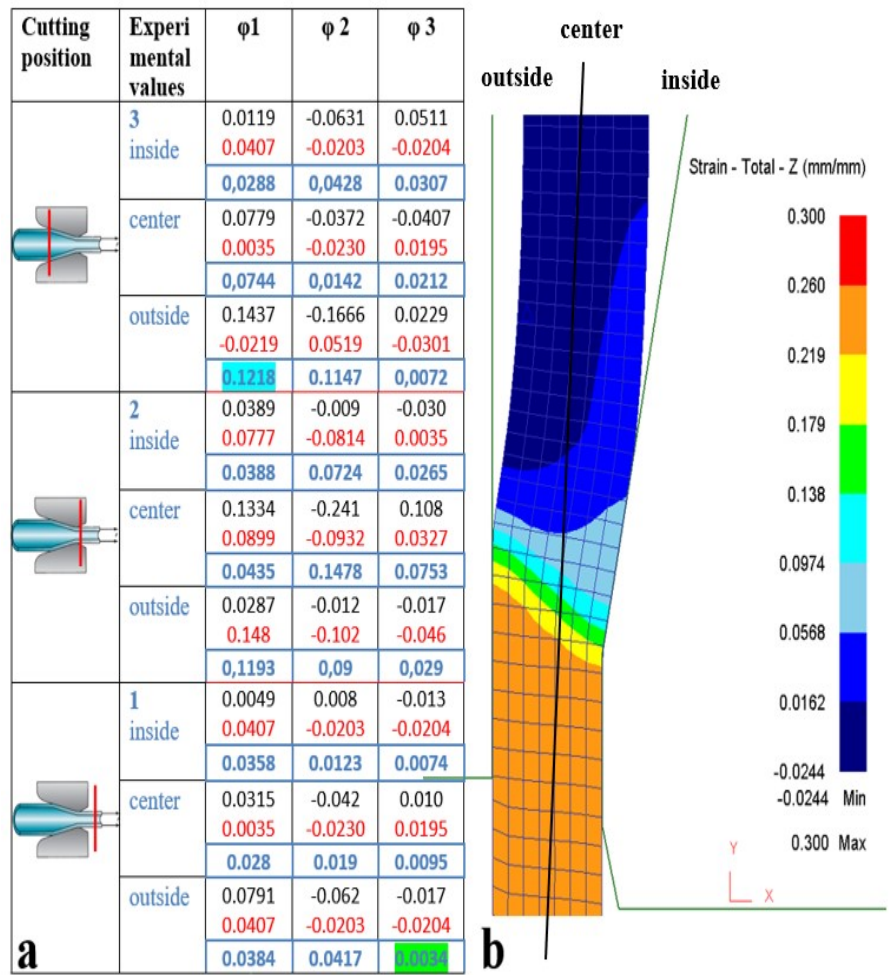

Figure 10. (a) Experimental values of local plastic deformation by stereology 1) drawn, 2) inside the die, and 3) enter to die; (b) distribution of local plastic deformations by simulation.

Up to $85 \%$ of the values of the differences (Figure $10 \mathrm{a}, 10 \mathrm{~b}$ ) do not reach the value of 0.1 , and according to the statistical T-test, all differences in the values of local plastic deformation were also evaluated as statistically insignificant, random $(\mathrm{P}>0.05)$.

\section{CONCLUSION}

The issue of studying the microstructure of a material after cold deformation within a volume is given extremely little attention in the world. However, the research is often focused only on the surface of the sample or deals with crystallographic orientation (structural anisotropy) and not the shape of microparticles (morphological anisotropy). This can be seen in several scientific papers (Zhank et al., 2018 \& Ghadbeigi et al., 2012 \& Saxena et al., 2015). In this research, the local plastic deformation in cold-deformed materials was quantitatively analyzed by the stereology method (Saltykov oriented test line method). More methods were developed to study structures by 2D imaging, which, as Martinkovič et al. claim, are not always economically efficient and cannot be used in all situations. These methods are not usually cheap, and their use can be more difficult, so it makes sense to look for simpler alternatives (Martinkovič et al., 2020). Stereological analysis was performed manually to exclude the measurement of unwanted artefacts in imperfect metallographic preparation. To solve numerical calculations of local plastic deformation, it was 
necessary, similarly to Miyoshi, E. et al., to use a mathematical model created by the Monte Carlo method (Miyoshi, 2018). For verification of the results obtained experimentally, simulations were implemented in the Deform simulation program like Hatala et al. (2020). The local plastic deformation can be measured in various ways, but the results described in this paper prove that stereology is a suitable and simple method to do that, which is confirmed by Zhang et al. (2005). In addition to that, the possibility of using the above-mentioned quantitative analysis to describe the local plastic deformation with a very small deviation was verified, resp. transformation at any point in the volume of the deformed material, confirmed by the simulation in software Deform. Based on the obtained results, it was confirmed that stereology is a suitable tool for evaluating local plastic deformation at any point in the volume of metallic material. It corresponds with Ueda's findings (Ueda, 2018). Greater application of stereological methods is documented in the field of biology or medicine and is even often used in technical fields due to its advantages. In this article, excellent compliance of local plastic values from stereological measurement and Deform simulation was achieved, as Karanjule et al. (2018). As Martinkovič, M. et al. suggest in their work, the results presented in this article will be used in further research, where the value of local strain $(\sigma)$ will be obtained from the calculations of the degree of orientation (O) (Martinkovič et al., 2020).

\section{ACKNOWLEDGMENT}

This publication was supported by the Slovak Research and Development Agency under the contract No. APVV-15-0319 and Operational Programme Research and Innovation for the project: Scientific and Research Centre of Excellence SlovakION for Material and Interdisciplinary Research, code of the project ITMS2014+: 313011W085 cofinanced by the European Regional Development Fund.

\section{REFERENCES}

Baddeley, A., Vedel Jensen E.B. 2005. Stereology For Statisticians, UK: Chapman \& Hall/CR

Foadian, F., Carradó, A., Pirling, T. \& Palkowski, H. 2016. Residual stresses evolution in Cu tubes, cold drawn with tilted dies. Materials \& Design, 107:163-170

Ghadbeigi, H., Pinna, C., Celotto, S. 2012. Comparison between Digital Image Correlation and Microgrid Techniques. Experimental Mechanics, vol. 52 (9): 1483-1492

Gokhale, A. M. 2019. Utility of Stereology for Quantitative Metallography. In: 100 Years of E04 Development of Metallography Standards, ed.: 37-52

Groover, M.P. 2011. Wire and bar drawing. In: Fundamentals of modern manufacturing: materials, processes and systems, 4th ed.: 442. Hoboken USA: John Wiley \& Sons, Inc.

Hatala, M., Botko, F., Peterka, J., Bella, P., Radic, P. 2020. Evaluation of strain in cold drawing of tubes with internally shaped surface. Materials Today: Proceedings, 22(2):287

Karanjule, D.B., Bhamare, S.S. \& Rao, T.H. 2018. Microstructure, Property Changes and Characterization for ST 35 Steel Material during Multiple Pass Cold Drawing Process of Seamless Tubes. Materials Today: Proceedings, 5(2): 7615 -7621

Martinkovič, M. 2017. Estimation and utilization of structure anisotropy in forming pieces. CeramicsSilikáty, 61(2): 141 - 146

Martinkovič, M., Minárik. S. 2020. On the problem of processing data from a cross-sectional image of grained structure. IOP Conf. Ser.: Mater. Sci. Eng., Poland: 727

Martinkovič, M., Minárik, S. 2018. Comparison of grain boundary orientation to deformation conversion models. In Development of Materials Science in Research and Education: 36. 
Martinkovič, M., Minárik, S. 2016. Short notes on the grain's modification by plastic deformation: 1-44. Hubbard D Plast Deform Nov Publ

Martinkovič, M., Minárik, S. 2017. Modelling of plastic deformation in polycrystalline material. In HutnikWiadomości Hutnicze. Vol. 84 (8): 371-373

Matoušek, T. 2015. Analysis of macrostructure of polymeric materials. Doctoral thesis.

Miyoshi, E., Takaki, T., Ohno, M. et al. 2018. Correlation between three-dimensional and cross-sectional characteristics of ideal grain growth. Journal of Materials Science, 53(21)

Necpal, M., Kapustová, M., Martinkovič, M. 2020. Using 2D/3D FEM Simulation to determine drawing force with straight internal rifling. In: Solid State Phenomena, 304: 121-125

Necpal, M., Martinkovič, M. 2019. Finite Element Modelling of Cold Drawing Inner Fined Tube, Published by DAAAM International Vienna, Austria

Necpal, M., Martinkovič, M. 2019. Evaluation of Material Deformation During Process of Precise Carbon Steel Tube Cold Draw Forming, IOP Conf. Ser.: Mater. Sci. Eng., Poland

Rønn-Nielsen, A., Sporring, J., Vedel Jensen, E.B. 2017. Estimation of sample spacing in stochastic processes. Image Analysis and Stereology, 36 (1): 43-49

Saxena, A. K., Tewari, A., Panta, P. 2015. Quantitative analysis of orientation and near neighbor interaction effects during deformation of Ti6Al4V. Mater. Sci. Eng. A, vol. 648: 1-8

Steel grades [cit. 2019-03-28]. Available on the Internet: http://www.feromat.cz/jakosti_oceli

Steel tubes [cit. 2019-03-28]. Available on the Internet: https://www.oceloverury.sk/

Tinius Olsen [cit. 2020-03-05]. Available on the Internet: https://www.tiniusolsen.com/list-of-products/model$300-$ st

Ueda, T., Oki, T., Koyanaka, S. 2018. 2D-3D conversion method for assessment of multiple characteristics of particle shape and size. Powder Technology, 343

Zhang, N., Mao, W. 2019. Study on the cold rolling deformation behavior of polycrystalline tungsten. International Journal of Refractory Metals and Hard Materials, vol. 80: 210-215 Zhang, X., Han, J. 2005. Analytic methods and theory of quantitative stereology for the determination of concrete proportioning. Cement and Concrete Research, 35(9): 1855-1858

Zhu, Q., Sellars, C.M. \& Bhadeshia, H.K.D.H. 2007. Quantitative metallography of deformed grains. In: Materials Science and Technology, 23(7): 757-766 